\title{
Wild Olive Trees Extent in Al-Baha Region, Saudi Arabia According to Trees' Age, Health, and Clustering Status
}

\author{
Abdullah Saleh Al-Ghamdi \\ Department of Biology, College of Sciences \\ Al-Baha University \\ Kingdom of Saudi Arabia \\ Email: abdullah.saleh.alghamdi [AT] gmail.com
}

\begin{abstract}
This study provided detailed information on the attributes of wild olive species in the Al-Baha region, Saudi Arabia. The study area lay along the Sarah mountain, encompassing the districts of Al-Qura, Al-Mandaq, AlBaha and the southern part of Baljurashi. This indicates the preference of wild olive for high foggy mountain conditions, which was pre-determined by the study to be a medium-high vegetation density zone. Information extracted from high resolution satellite imagery Pleaides revealed that there are 717,894 wild olive trees (360 trees per $\mathrm{km} 2)$ in the study area, covering 1,991 km2 .The districts of Al-Mandaq and Al-Baha have higher wild olive density with younger and highly clustered trees, whereas Al-Qura and Baljurashi districts have lower wild olive density, with medium clustered older trees. The districts of Al-Aqiq, Qelwa and Mekhwa have the least density of wild olive with younger trees and light clustering. Clustering behavior was enumerated directly at the sampling plots and the results depicted that the majority of wild olives occur in clusters with mostly 5-10 trees per cluster. The olive tree is found naturally in Al-Baha and can reportedly maintain its populations in natural old growth forests for several hundred years. This study identified the age of wild olive trees in the study area. The results indicated that there were more (68\%) of young age class (<50 years old) of wild olive trees, whereas Baljurashi showed the highest percentage of old age class (>150 years). The majority $(88.6 \%)$ of the wild olive trees were healthy, while more unhealthy trees were observed in Al-Mandaq and Al-Baha districts. As observed during the groundwork, unhealthy trees particularly due to dieback, were more discerned with juniper affecting vegetation in Al-Mandaq and South Baha, with $45 \%$ and $18 \%$ respectively. Similarly, this study recorded trace of unhealthy vegetation, with $11.4 \%$ of the wild olive trees in an unhealthy condition. This information would be essential in 'Identifying the Landscape Preference of Wild Olive in Al-Baha Region Saudi Arabia'.
\end{abstract}

Keywords --- Wild olive tree, Extent, Al-Baha region, Saudi Arabia, treeclustering, tree age, tree health.

\section{INTRODUCTION}

\subsection{Wild Olive Tree}

Olea oleaster, the wild-olive, has been considered by various botanists as a valid species and a sub-species-of the cultivated olive tree, Olea europea, which has multiple origins (Besnard, and Berville, 2000) and was domesticated, it now appears, at various places during the fourth and third millennia BCE, in selections drawn from varying local populations (Besnard, and Baradat, 2001).

Today, as a result of natural hybridization, very ancient domestication and extensive cultivation of the olive throughout the Mediterranean Basin, wild-looking feral forms of olive, called "oleasters", constitute a complex of populations, ranging from feral forms to the wild olive. (Lumaret, Ouazzani, Michaud, and Vivie,2004).

The wild olive is a tree of the maquis shrubland, in part the result of the long human presence. The droughttolerant sclerophyllous wild olive tree is believed to have originated in the Mediterranean Basin. It still provides the hardy and disease-resistant rootstock, on which cultivated olive varieties are grafted (Breton, et al., 2006).

The wild olive is also reported to be native to the North American evergreen tree, which reaches a 20-foot height with a10-to15 foot spread. This tree is very rarely found and is even reportedly close to extinction. Theolive-likewhitefruitsthat are produced have a sweet flesh relished by birds and other wildlife and, although edible for humans, should not be eaten in quantities. However, in the United States of America, another olive species known as the Russian olive (Elaeagnus angustifolia L.) was considered an exotic invasive weed. This thorny shrub or tree originated from South-eastern Europe and Western Asia, as reported by Katz and Shafroth (2003) as intentionally introduced and planted in the United States for windbreaks, erosion control, wildlife habitat, and other horticultural purposes. This tree was then observed to be very 
well adapted to semi-arid and saline environments. Early in the $20^{\text {th }}$ century, Russian olive cultivation spread, particularly into the large moist riparianenvironmentsinaridorsemi-aridregionsofthewesternUnitedStates(Stannardet al, 2002).

\subsection{Study Area}

The most effective way to map plant-species ranges in an area is by demarcating a general bioclimatic envelope within biogeographic regions, in which a species is known to have been found. This study requires building a database of species that includes data on the distribution of the species by geographic region, major habitat type, and elevation range (Price, 2004).

Similarly, in this study, due to the large area involved and to save time, cost and energy, the study selected only areas with a high probability of wild olive tree presence, indicated by high $\left(62 \mathrm{~km}^{2}\right)$ and medium $\left(766 \mathrm{~km}^{2}\right)$ density vegetated area. However, there is also a possibility of the wild olive tree being found at nearby lower vegetation density area. Hence, the study area was expanded to the northern part low vegetation canopy density, but not to the southern part, because the southern part of Al-Mekhwah and Qelwa has a steep slope towards Tehama. This brought the overall study area to $1,991 \mathrm{~km}^{2}$ (Figure 1), which is just $18.0 \%$ of the whole Al-Baha region. The study area covers almost all areas of A-Mandaq and Al-Baha districts, with $58.5 \%$ of the study area having low Vegetation Crown Density (AlGhamdi, 2020)study Area (in red).

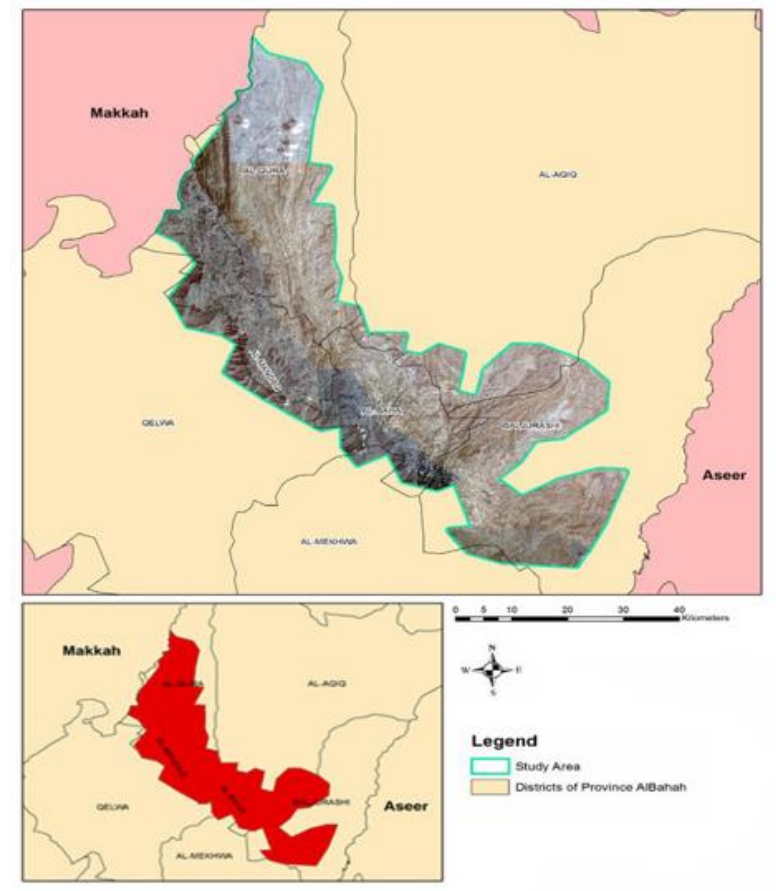

Figure 1: Study Area

Table 1: Study area extent according to districts

\begin{tabular}{|c|c|c|c|c|c|c|c|c|c|}
\hline \multicolumn{2}{|c|}{ District } & \multicolumn{4}{c|}{ Vegetation Canopy Density } & \multicolumn{3}{c|}{ Study Area } \\
\hline Name & KM $^{2}$ & High & $(\%)$ & Med. & $(\%)$ & Low & $(\%)$ & KM $^{2}$ & $(\%)$ \\
\hline Al-Qura & 1,049 & 9 & 1.5 & 128 & 21.8 & 449 & 76.6 & 586 & 55.9 \\
\hline Al-Aqiq & 3,667 & 0 & 0.0 & 21 & 12.7 & 144 & 87.3 & 165 & 4.5 \\
\hline Al-Mandaq & 361 & 23 & 6.8 & 247 & 72.9 & 69 & 20.4 & 339 & 94 \\
\hline Al-Mekhwa & 1,949 & 3 & 11.1 & 24 & 88.9 & 0 & 0.0 & 27 & 1.4 \\
\hline Al-Baha & 298 & 17 & 5.9 & 106 & 36.9 & 164 & 57.1 & 287 & 96.4 \\
\hline Baljurashi & 1,505 & 7 & 1.4 & 162 & 32.0 & 337 & 66.6 & 506 & 33.6 \\
\hline Qelwa & 2,232 & 3 & 3.7 & 78 & 96.3 & 0 & 0.0 & 81 & 3.6 \\
\hline TOTAL & $\mathbf{1 1 , 0 6 0}$ & $\mathbf{6 2}$ & $\mathbf{3 . 1}$ & $\mathbf{7 6 6}$ & $\mathbf{3 8 . 5}$ & $\mathbf{1 , 1 6 3}$ & $\mathbf{5 8 . 4}$ & $\mathbf{1 , 9 9 1}$ & $\mathbf{1 8}$ \\
\hline
\end{tabular}




\subsection{Objectives}

The primary aim of this study is to identify wild olive attributes to support a wide variety of resource assessment, management, and conservation. This study can be a guide for a standard national vegetation classification scheme and mapping protocols that will facilitate effective resource management, by ensuring compatibility and widespread use of the information at multiple geographic scales throughout Al-Baha federal and provincial agencies.

This wild olive inventory study involves field collection to classify the species pre-determined to be of medium-high vegetation density across the Al-Baha region. To better understand the status and to support researchers and decision makers to develop strategies and remedies, it is necessary to obtain accurate spatial information on the progression of this species. The purpose of this project is to acquire information regarding the wild olive tree locations and attributes in the Al-Baha region.

\section{MATERIAL AND METHOD}

\subsection{Ground Sample Collection.}

Ground sample collection activity is required to acquire several locations of the wild olive tree at various district sites to be the 'training samples' for supervised classification. These locations were marked as wild olive tree coordinates on the image and the spectral signature or digital number were recognised as a guide to search and demarcate other similar reflectance characteristics. In this study, about 30 points of wild olive tree were to run supervised classification.

\subsection{Forest Inventory Design.}

In this study, wild olive inventory was based on ground inventory sampling plot. A certain number of plots statistically representing the whole area were randomly selected at site and $100 \%$ measurement taken within the plot. The inventory process comprises designing the inventory, designing the forms for collecting the information, dividing the forest area into seven districts, describing the tree cover of each site, measuring all the trees and shrubs in each sampling plot and analyzing the information obtained.

\subsection{Accuracy Assessment.}

Accuracy assessment is the comparison of a classification with ground truth data, to evaluate how well the classification represents the real world. The steps involved in accuracy assessment include determining the number of samplings, determining confidence building assessment and sampling design. In this project, the number of sampling units follows the method of Krejcie and Morgan (1970), with plots selected based on Random Sampling technique.

\subsection{Determining the Number of Sampling Units Required for the Inventory.}

The sample size of any study must be determined during the designing stage of the study. However, before determining the size of the sample to be drawn from the population, a few factors must be considered. According to Salant and Dillman (1994), the size of the sample is determined by four factors:

- the extent of tolerable sampling error.

- population size.

- how varied the population is, with respect to the characteristics of interest.

- the smallest subgroup within the sample for which estimates are needed.

The following section used the aforesaid methods as a guideline, along with the method of Krejcie and Morgan (1970) and Cohen, J. (1988).

\subsection{Krejcie and Morgan}

Estimation of the sample size in research using the following formula of Krejcie and Morgan (1970) is commonly adopted.:

$S=X^{2} N P(1-P) / d^{2}(N-1)+X^{2} P(1-P)$. 
$\mathrm{S}=$ required sample size .

$\mathrm{X}^{2}=$ thetablevalueofchi-squareforonedegreeoffreedomatthedesiredconfidencelevel.

$\mathrm{N}=$ the population size

$\mathrm{P}=$ the population proportion (assumed to be .50 since this would provide the maximum sample size)

$\mathrm{d}=$ the degree of accuracy expressed as a proportion (.05)

In this study,

$\mathrm{S}=\mathrm{X}^{2} \mathrm{NP}(1-\mathrm{P}) / \mathrm{d}^{2}(\mathrm{~N}-1)+\mathrm{X}^{2} \mathrm{P}(1-\mathrm{P})$

$=3.841 * 236,250 * 0.95 *(1-0.95) / 0.05 * 0.05 *(236,250-1)$

$=41,963 / 575.18$

$=73$

Therefore, a total of 73 plots of $50 \mathrm{~m} \times 50 \mathrm{~m}$ were established in the study area.

\subsection{Determining Sample Size.}

Each sample point collected is expensive and therefore the sample size must be kept to the minimum; however, it is critical to maintain a large enough sample size, so that any analysis performed is statistically valid. The traditional thinking about sampling does not often apply (Congalton, 1991). Hence, this project followed the most common plot size of 50m x 50m established for forest inventory, applied also by El-Juhany, and Aref (2012) for recent inventory vegetation in Al-Baha.

\subsection{Tree Attribute Measurement /Enumeration.}

Tree attribute measurement and enumeration were done by direct measurement on the ground. Characteristics of tree age, tree health and tree clustering were directly measured at ground. Ground measurements were conducted during October 2016 with 73 plots of $50 \mathrm{~m} \times 50 \mathrm{~m}$. Techniques for each tree were as per the characteristics shown below:

\subsection{Tree number per cluster.}

Measurement/enumeration techniques: Enumeration was conducted directly at the plot site, based on visual observations within a $5 \mathrm{~m}$ radial distance from the olive tree. Total tree numbers in the entire study area were than calculated based on the percentage of cluster class at the plots. In this study, the tree number per group was categorized as follows:

- Light Cluster $(<5$ trees / cluster).

- Medium Cluster(6-10 trees/cluster).

- Heavy Cluster (>11 trees/cluster).

\subsection{Tree Age Status.}

Measurement / enumeration techniques: The age of the tree was estimated directly at the plot site, based on local experts' opinion and size of the tree.

Total tree numbers in the study area were than calculated based on the percentage of age class at the plots. In this project, age class was categorized as follows:

- $\quad 1-50$ year-old

- $\quad$ 50-100 year-old

- $\quad>100$ yearsold.

\subsection{Tree Health Status.}

Measurement / enumeration techniques: The health status of a tree was determined digitally by the ERDAS software, by identifying its reflectance value (digital number) which is higher when it is unhealthy and appears brown in the infra-red image. 


\subsection{Stratified Random Sampling.}

From the vegetation map generated from the first phase study, it was observed that the districts of Al-Baha have varied vegetation density, much influenced by elevation. We may hence expect the measurement of wild olive trees to vary among the different districts. This has to be considered when we select a sample from the population, to ensure that the sample is representative of the population. This can be achieved by stratified sampling. A stratified sample is obtained by taking samples from each stratum or sub-group of a population. When we sample a population with several strata, we generally require that the proportion of each stratum in the sample should be the same as in the population.

Stratified sampling techniques are generally used when the population is heterogeneous or dissimilar, where certain homogeneous, or similar sub-populations (strata) can be isolated. Simple random sampling is most appropriate when the entire population from which the sample is taken is homogeneous. Some reasons for preferring stratified sampling to simple random sampling are:

the cost per observation in the survey may be reduced;

estimates of the population parameters may be required for each sub-population;

increased accuracy at given cost.

As mentioned earlier, stratification was based on district boundaries and the numbers of plots are in proportion to the district size. As the major portion of the study area is on a high elevation mountain with a not easily accessible rugged terrain, accessibility and road proximity have to be considered in the selection of plots. Trees a bit deeper in the plot were remotely measured by using a laser range finder. In this study, verification was conducted on the accuracy of the satellite image interpreted wild olive trees, which was indicated as $100 \%$ throughout the whole study area. We used the same 73 inventory plots identified earlier, to save time and energy (Figure 2).

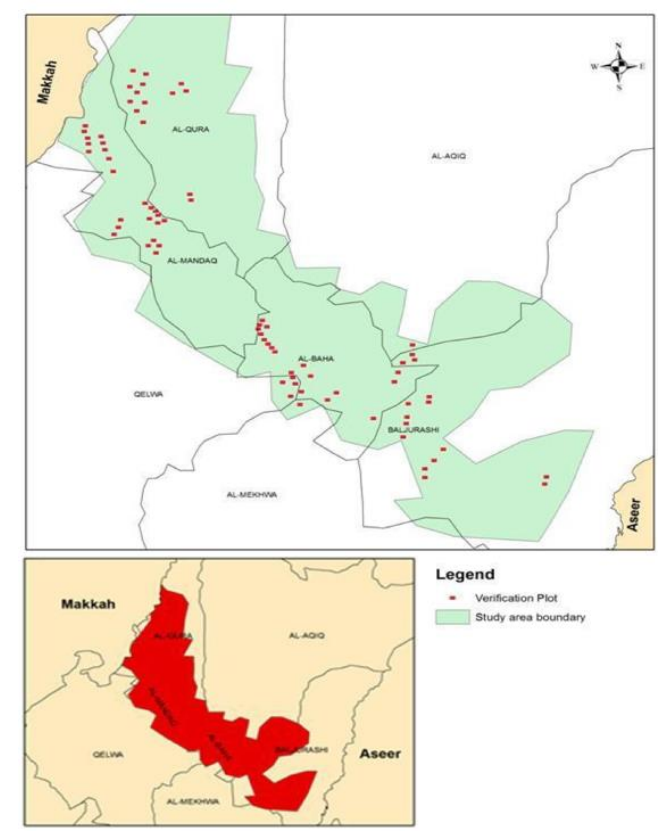

Figure 2: Location of Plots for Inventory and Accuracy Assessment.

\section{RESULT}

\subsection{Extent of wild olive tree according to Health Status}

In this study, health status was determined by field observation at the plot, in which a tree that appeared worse than half sick, with brownish leaves and irregular growth, was considered as unhealthy, and others, healthy. The results show that $88.5 \%$ or 635,235 wild olive trees were healthy. Unhealthy trees were seen more at Al-Mandaq (16.3\%) and Al-Baha (11.4\%), probably due to developmental pressure, since these two districts are considered more developed in the Al Baha region. Besides, since these are more densely populated, wild olive trees have been cut down for fuel supply, leaving them in an unhealthy condition. The number of unhealthy trees in other districts is not so significant. Table 2 shows details of the categories. 
Table 2: Extent of Wild Olive Tree Health Status

\begin{tabular}{|c|c|c|c|c|c|c|c|c|}
\hline \multirow{3}{*}{ District } & \multirow{3}{*}{$\begin{array}{c}\text { No of } \\
\text { plots }\end{array}$} & \multirow{3}{*}{$\begin{array}{l}\text { Total Number } \\
\text { of Trees atPlot }\end{array}$} & \multicolumn{5}{|c|}{ Number of Wild Olive Trees } & \\
\hline & & & \multicolumn{3}{|c|}{ Not Healthy } & \multicolumn{3}{|c|}{ Healthy } \\
\hline & & & Tree at plot & $(\%)$ & Total tree & Tree at plot & $(\%)$ & Total trees \\
\hline Al-Qura & 13 & 91 & 7 & 7.7 & 9,993 & 84 & 92.3 & 119,910 \\
\hline Al-Aqiq & 1 & 5 & 1 & 0.0 & - & 4 & 0.0 & - \\
\hline Al-Mandaq & 24 & 166 & 27 & 16.3 & 33,837 & 139 & 83.7 & 174,197 \\
\hline Mekhwa & 1 & 2 & 0 & 0.0 & - & 2 & 100.0 & 11,851 \\
\hline Al-Baha & 15 & 105 & 12 & 11.4 & 18,492 & 93 & 88.6 & 143,310 \\
\hline Baljurashi & 15 & 78 & 5 & 6.4 & 11,462 & 73 & 93.6 & 167,339 \\
\hline Qelwa & 4 & 22 & 2 & 9.1 & 2,188 & 20 & 90.9 & 21,882 \\
\hline TOTAL & 73 & 469 & 54 & $\mathbf{1 1 . 5}$ & 82,657 & 415 & 88.5 & 635,237 \\
\hline
\end{tabular}

\subsection{Extentof wildolivetrees according toClustering Category}

Clustering characteristics of the wild olive tree in Al-Baha were observed at the sample plots and later extrapolated to provide the total number of trees according to clustering category in the study area. In this study, three clustering classes were established, light cluster (1-5 trees/cluster), medium cluster (6-10 trees/cluster) and heavy cluster (more than 11 trees/cluster). Results analysed reveal that wild olive trees are quite clustered in occurrence, with the highest proportion (39.4\%) belonging to the medium cluster (6- 10 trees/cluster) and 33.3\% to the heavy cluster (>11 trees/cluster). As shown in Table 3, wild olive trees occurred in heavy cluster in Al-Mandaq and Al-Baha, with 45.2\% and 42.9\% respectively. This may contribute to these districts having highly dense wild olive trees, as shown in Table 3. Trees at Al-Aqiq and AlMekhwa were seen in only small clusters, with no heavy cluster in Baljurahi and Qelwa districts. Heavy clusters of wild olive trees were found only in Al- Qura, Al-Mandaq and Al-Baha. However, Baljurashi had the highest percentage $(66.7 \%)$ of medium cluster.

Table 3: Extent of Wild Olive Trees According to Clustering Category

\begin{tabular}{|c|c|c|c|c|c|c|c|c|c|c|c|}
\hline \multirow{3}{*}{ District } & \multirow{3}{*}{$\begin{array}{l}\text { No } \\
\text { of } \\
\text { plots }\end{array}$} & \multirow{3}{*}{$\begin{array}{c}\text { Number of } \\
\text { wild } \\
\text { olive } \\
\text { trees in } \\
\text { plots }\end{array}$} & \multicolumn{9}{|c|}{ Number of Trees } \\
\hline & & & \multicolumn{3}{|c|}{$\begin{array}{c}\text { Light cluster } \\
\text { (1-5 trees/cluster) }\end{array}$} & \multicolumn{3}{|c|}{$\begin{array}{l}\text { Medium cluster } \\
\text { (6-10 trees/cluster) }\end{array}$} & \multicolumn{3}{|c|}{$\begin{array}{c}\text { Heavy cluster } \\
\text { (>11 trees/cluster) }\end{array}$} \\
\hline & & & $\begin{array}{c}\text { Trees at } \\
\text { plot }\end{array}$ & $\begin{array}{l}\% \text { trees } \\
\text { at plot }\end{array}$ & Total trees & $\begin{array}{c}\text { Trees } \\
\text { at plot }\end{array}$ & $\begin{array}{l}\% \text { Tree } \\
\text { at plot }\end{array}$ & $\begin{array}{l}\text { Total } \\
\text { trees }\end{array}$ & $\begin{array}{c}\text { Trees at } \\
\text { plot }\end{array}$ & $\begin{array}{l}\% \text { Trees } \\
\text { at plot }\end{array}$ & \begin{tabular}{|c|} 
Total \\
Trees
\end{tabular} \\
\hline Al-Qura & 13 & 91 & 28 & 30.8 & 39,970 & 27 & 29.7 & 38,543 & 36 & 39.6 & 51,390 \\
\hline Al-Aqiq & 1 & $\overline{5}$ & 5 & 100.0 & 3,433 & 0 & 0.0 & 0 & 0 & 0.0 & 0 \\
\hline Al-Mandaq & 24 & 166 & 38 & 22.9 & 47,622 & 53 & 31.9 & 66,420 & $\overline{75}$ & 45.2 & 93,991 \\
\hline Al-Mekhwa & 1 & 2 & 2 & 100.0 & 11,851 & 0 & 0.0 & 0 & 0 & 0.0 & 0 \\
\hline Al-Baha & 15 & 105 & 17 & 16.2 & 26,197 & 43 & 41.0 & 66,262 & 45 & 42.9 & 69,344 \\
\hline Baljurashi & 15 & 78 & 26 & 33.3 & 59,600 & 52 & 66.7 & 119,201 & 0 & 0.0 & 0 \\
\hline Qelwa & 4 & 22 & 12 & 54.5 & 13,129 & 10 & 45.5 & 10,941 & 0 & 0.0 & 0 \\
\hline TOTAL & 73 & 469 & 128 & 27.3 & 201,802 & 185 & 39.4 & 301,366 & 156 & 33.3 & 214,725 \\
\hline
\end{tabular}


Table4: Extent of Wild Olive Trees Categorized by Age

\begin{tabular}{|c|c|c|c|c|c|c|c|c|c|c|c|}
\hline \multirow[b]{3}{*}{ District } & \multirow{3}{*}{$\begin{array}{c}\text { No } \\
\text { of } \\
\text { plots }\end{array}$} & \multirow{3}{*}{$\begin{array}{c}\text { Number } \\
\text { of } \\
\text { wild } \\
\text { olive } \\
\text { trees at } \\
\text { plots }\end{array}$} & \multicolumn{9}{|c|}{ Number of Trees } \\
\hline & & & \multicolumn{3}{|c|}{ (1-50 yrs.) } & \multicolumn{3}{|c|}{ (51-100 yrs.) } & \multicolumn{3}{|c|}{ (>101 yrs.) } \\
\hline & & & $\begin{array}{c}\text { Trees } \\
\text { at } \\
\text { plot }\end{array}$ & $(\%)$ & $\begin{array}{l}\text { Total } \\
\text { trees }\end{array}$ & $\begin{array}{c}\text { Trees } \\
\text { at } \\
\text { plot }\end{array}$ & $(\%)$ & $\begin{array}{l}\text { Total } \\
\text { trees }\end{array}$ & $\begin{array}{c}\text { Trees } \\
\text { at } \\
\text { plot }\end{array}$ & $(\%)$ & $\begin{array}{l}\text { Total } \\
\text { trees }\end{array}$ \\
\hline Al-Qura & 13 & 91 & 74 & 81.3 & 105,635 & 14 & 15.4 & 19,985 & 3 & 3.3 & 4,283 \\
\hline Al-Aqiq & 1 & 5 & 5 & 100.0 & 3,433 & 0 & 0.0 & 0 & 0 & 0.0 & 0 \\
\hline Al-Mandaq & 24 & 166 & 113 & 68.1 & 141,614 & 42 & 25.3 & 52,635 & 11 & 6.6 & 13,785 \\
\hline Al-Mekhwa & 1 & 2 & 2 & 100.0 & 11,851 & $\overline{0}$ & 0.0 & $\overline{0}$ & 0 & 0.0 & $\overline{0}$ \\
\hline Al-Baha & 15 & 105 & 65 & 61.9 & 100,163 & 28 & 26.7 & 43,147 & 12 & 11.4 & 18,492 \\
\hline Baljurashi & 15 & 78 & 38 & 48.7 & 87,108 & 27 & 34.6 & 61,893 & 13 & 16.7 & 29,800 \\
\hline Qelwa & 4 & 22 & 22 & 100.0 & 24,070 & 0 & 0.0 & 0 & 0 & 0.0 & 0 \\
\hline TOTAL & 73 & 469 & 319 & 68.0 & 488,290 & 111 & 23.7 & 169,907 & 39 & 8.3 & 59,697 \\
\hline
\end{tabular}

\subsection{Extent of wild olive trees according to Age Category}

In this study, age categories were determined by field observation at the plot, based on tree size and local knowledge and later extrapolated to provide the total number of trees in the study area. Age was divided into three classes: young (1-50 years), medium (51-100 years) and old (> 100 years). Overall results show that most (488,290 trees or 68.0\%) wild olive trees in AlBaha are less than 50 year- old and only 59,697 (8.3\%) were more than 100 year -old. More older trees were observed at Baljurashi, with 34.6\% of them being 51-100 year - old and 16.7\% more than 100 year - old (Table 4). This is probably due to the presence of inaccessibly high mountains, which are less developed at Baljurashi district. There are no trees older than 50 years at Al-Aqiq and Qelwa. However, this observation and presumption are probably indicated more by the crown diameter size characteristic.

\section{DISCUSSION}

Information extracted from high resolution satellite imagery Pleaides revealed that there are 717,894 wild olive trees (360 trees per $\mathrm{km}^{2}$ ) in this study area covering $1,991 \mathrm{~km}^{2}$, mostly found in mountainous areas in Al-Mandaq and AlBaha districts. Al-Khulaidy (2013) found this region to be the most plant-diversified area in Saudi Arabia. Earlier, ElJuhany and M Aref (2012) inventoried 147 all species trees per ha in Al- Mandaq, whereas this study counted 613 wild olive trees per $\mathrm{km} 2$. This indicates that wild olive is not the main species of vegetation in Al-Baha region.

\subsection{Clustering}

Clustering behaviour was enumerated directly at the sampling plots and the results indicated that the majority of wild olive trees occur mostly in clusters of 5-10 trees each.

\subsection{Age Status.}

The Olive tree is found naturally at Al-Baha, and can maintain its populations in natural old growth forests for up to several hundred years. This study identified the age of wild olive trees in the study area. Results showed the existence of more $(68 \%)$ of young olive trees ( $<50$ years old), while Baljurashi showed the highest percentage of old trees $(>150$ years). This indicates that the high Rocky Mountains at Baljurashi have suffered less developmental pressure, compared to Al-Mandaq and Al-Baha districts.

\subsection{Health status}

According to El-Johauny Loufty (2015), Juniperus procera is the most abundant species in Al-Baha region, but has been suffering from varying degrees and types of degradation, due to both human-induced and natural factors, as well as dieback disease. Hence, this study investigated whether wild olive faced a similar condition. Results showed that a majority $(88.6 \%)$ of the wild olive trees were healthy, with more unhealthy trees observed in both Al-Mandaq and AlBaha districts, probably due to developmental pressure. As observed during groundwork and as reported by Al-Johauny Loufty (2015), unhealthy trees particularly due to dieback were more discerned in Juniper, affecting vegetation in Al- 
Mandaq and South Baha, with $45 \%$ and $18 \%$ respectively. Similarly, this study recorded traces of unhealthy vegetation, with $11.4 \%$ of wild olive trees found in unhealthy condition, indicating signs of vegetation degradation in Al-Baha region, which needs to be addressed by the authorities.

\section{CONCLUSION}

This study has provided detailed information on the species attributes. Results obtained show that wild olive occurrence can be divided into three zones; (i) districts of Al-Mandaq and Al-Baha, which have higher wild olive density with highly clustered young trees, (ii) while the districts of Al-Qura and Al-Baljurashi have lower wild olive density, with medium clustered older trees, and (iii) the districts of Al-Aqiq, Qelwa and Mekhwa have the least dense wild olive with lightly clustered younger trees.

The life-form distribution of plants growing in arid regions is closely related to their topography and landform (Aldhebiani, and Howladar, 2013). This information will be essential to further study to identifying the Landscape Preference of Wild Olive in the Al-Baha Region.

\section{ACKNOWLEDGEMENTS}

This research was funded by the Chair of Sheikh Said Ben Ali Alangari for olives research at Albaha University, Albaha, Saudi Arabia. The Author also acknowledges with thanks the Dean of Scientific Research (DSP) at Albaha University for the technical support. Author's thanks are due also to Geoprecision Tech Sdn Bhd (GPT) and Universiti Putra Malaysia (UPM) for their technical assistance.

\section{REFERENCES}

[1] Al-Ghamdi Abdullah Saleh. Classifying and Mapping of Vegetated Area in Al- Baha Region, Saudi Arabia Using Remote Sensing. I. Extent and Distribution of Ground Vegetated Cover Categories. Indian Journal of Applied Research, Vol. 10, no12. pp. 75-80. 2020.

[2] Al-Khulaidi A.A. Flora of Yemen. The Sustainable Natural Resource Management Project (SNRMP II), EPA and UNDP, Republic of Yemen. 2013.

[3] Aldhebiani, A. Y., Howladar S. M. Floristic Diversity and Environmental Relations in Two Valleys, South West Saudi Arabia, International Journal of Science and Research (IJSR), Vol, no. 4 2, February 2015, ISSN (Online): 2319-7064. 2013.

[4] Besnard, G. Baradat, Genetic relationships in the olive (Olea europaea L. reflect multilocal selection of cultivars, Theoretical and Applied Genetics, Vol. 102, No. (2/3). pp. 251-258. 2001.

[5] Besnard, G., and André Berville, Multiple origins for Mediterranean olive (Olea europaea L. ssp. europaea) DNA polymorphisms Comates Rendus de l'Académie des Sciences, Vol. 323, No 2. pp. 173-181. 2000.

[6] Breton Catherine Marie, Michel Tersac and, André Jean Bervillé, Genetic diversity and gene flow between the wild olive (oleaster, Olea europaea L.) and the olive: Several Plio-Pleistocene refuge zones in the Mediterranean basin suggested by simple sequence repeats analysis. Journal of Biogeography Vol. 33, No.11. pp. 1916-1928. 2006.

[7] Cohen, J. Statistical power analysis for the behavioral sciences. Second Edition. Hillsdale, NJ: Lawrence Erlbaum Associates, Publishers. 1988.

[8] Congalton R.G., A Review of Assessing the Accuracy of Classifications of Remotely Sensed Data, remote sense Environ. 37, pp. 35-46.1991.

[9] El-Juhany, L. I. and I. M. Aref. The Present Status of the Natural Forests in the Southwestern Saudi Arabia 2-Baha Forests. World Applied Sciences Journal (ISI Journal) vol. 20 no. 2, pp. 271-281. ISSN 1818-4952. 2012.

[10] El-Juhany, Loutfy. The Magnitude of Dieback on Juniperus procera Trees in the Natural Forests in the Southwestern Region of Saudi Arabia, biosciences biotechnology research ASIA, Vol. 12 no.1, 219-230. 2015. 
[11] Katz, Gabrielle. L., Shafroth, Patrick B. Biology, ecology and management of Elaeagnus angustifolia L. (Russian olive) in western North America. Wetlands, Vol. 23, no. 4, pp. 763-777. 2003.

[12] Krejcie, R. V., \& Morgan, D. W. Determining sample size for research activities. Educational and Psychological Measurement, 30, pp.607-610. 1970.

[13]Lumaret, R., Ouazzani, N., Michaud, H., Vivier, G., Deguilloux, M. F. and Di Giusto, F. , Allozyme variation of oleaster populations (wild olive tree) (Olea europaea L.) in the Mediterranean Basin. Heredity, Vol. 92, pp. 343351.2004

[14]Price, J. P. Floristic biogeography of the Hawaiian Islands: Influences of area, environment and paleogeography. Journal of Biogeography Vol., 31. pp. 487-500. 2004.

[15] Salant,P.,\&Dillman,D.A.Howtoconductyourownsurvey.NewYork:JohnWiley\&Sons, Inc. 1994.

[16] Stannard, Mark, Ogle, Dan, Holzworth, Larry, Scianna, Joe, Sunleaf, Emmy. (). History, biology, ecology, suppression and revegetation of Russian-olive sites (Elaeagnus angustifolia L.). Technical Notes. Plant Materials No. 47. Boise, ID: U.S. Department of Agriculture, Natural Resources Conservation Service. 14 p. [53196] 2002. 